\title{
African Easterly Waves and Cyclonic Activity over the Eastern Atlantic: Composite and Case Studies
}

\author{
Moctar Camara, ${ }^{1}$ Arona Diedhiou, ${ }^{2}$ and Amadou Gaye ${ }^{3}$ \\ ${ }^{1}$ Laboratoire d'Océanographie, des Sciences de l'Environnement et du Climat (LOSEC), Université de Ziguinchor, \\ BP 523, Ziguinchor, Senegal \\ ${ }^{2}$ IRD-LTHE, Université de Grenoble, BP 53, 38041 Grenoble Cedex 9, France \\ ${ }^{3}$ LPAO-SF, ESP-UCAD, BP 5085, Dakar-Fann, Senegal \\ Correspondence should be addressed to Arona Diedhiou, arona.diedhiou@ird.fr
}

Received 25 February 2011; Revised 17 July 2011; Accepted 20 August 2011

Academic Editor: Gregory S. Jenkins

Copyright () 2011 Moctar Camara et al. This is an open access article distributed under the Creative Commons Attribution License, which permits unrestricted use, distribution, and reproduction in any medium, provided the original work is properly cited.

\begin{abstract}
This study aims to understand the main differences over the African continent and the Eastern Atlantic Ocean between African Easterly Waves (AEWs) associated with Atlantic cyclones (developing AEWs) and non-developing AEWs. A statistical study showed that most of the named cyclones generated near the West African coast have a long lifecycle and all are associated with intense AEWs. Using NCEP/NCAR reanalyses, a composite study of the characteristics of developing AEWs is carried out and compared to those of non-developing AEWs. Developing AEWs exhibit the greatest baroclinic and barotropic conversions which are known to be the main processes involved in AEWs growth suggesting that these AEWs are stronger than the non-developing ones. Moreover, the developing AEWs are characterized by the existence of a relatively more unstable environment over West Africa and the Atlantic Ocean. A case study using rawinsonde data showed that the developing AEW is associated with dynamic and thermodynamic conditions conducive for deep convection and subsequent cyclogenesis compared to the non-developing AEW case.
\end{abstract}

\section{Introduction}

Gray et al. [1,2] suggested some necessary but not sufficient conditions for the initiation of North Atlantic tropical cyclones (TCs): warm waters (at least $26^{\circ} \mathrm{C}$ ), an atmosphere which cools fast enough with height, a high mid-levels humidity because dry air layer at middle levels is not conducive for promoting the development of deep convection, and a low vertical wind shear between the low and upper troposphere. Moreover, a minimum distance of at least $500 \mathrm{~km}$ from the equator (nonnegligible amounts of Coriolis force) is required to maintain the circulation of the disturbance. To develop, a tropical cyclone needs a precursor. African Easterly Waves (AEWs, hereinafter) are the main precursors of cyclonic activity over the North Atlantic [3-7].

AEWs are important features of the West African region and tropical Atlantic Ocean. They propagate westward with a period of 3-5 days and are generated by a mixed baroclinic-barotropic instability of the African Easterly Jet [8].
Thorncroft et al. [9] suggested that these synoptic disturbances tend to be triggered by convection over orographic regions of East Africa. Their associated cyclonic vortices usually propagate along two tracks over West Africa (North and South of the AEJ) and merge into one over the North Atlantic Ocean $[10,11]$. AEWs are also known to modulate Mesoscal Convective Systems activity and the daily rainfall over West Africa [12-15].

Many studies have focused on the role of large-scale environment such as sea surface temperature, vertical wind shear, and mid-levels humidity on tropical cyclogenesis $[2,16,17]$. Several studies have been done to address the links between AEWs and North Atlantic tropical cyclones genesis and these studies mainly focused on the relation between the number of AEWs that cross the West African coast and subsequent tropical cyclogenesis. Thorncroft and Hodges [18] showed that on an interannual timescale the relationship between the number of AEWs and North Atlantic TCs is not significant enough to explain all the 
variability of cyclonic activity over the North Atlantic Ocean. Avila and Pasch [19] found that although the number of AEWs in the tropical Atlantic is fairly constant from year to year, there is a substantial variability in the fraction of AEWs that develop into tropical cyclones [19]. For an example, during the 2002 (1996) Atlantic hurricane season, $10 \%(92 \%)$ of cyclones developed from AEWs [20, 21].

Hopsch et al. [22] in a pioneer work, instead of continuing to focus on the relation between the number of AEWs and tropical cyclones, studied composite structures of AEWs that developed into named tropical cyclones and nondeveloping AEWs using ERA-40 reanalysis data. They found that the lack of AEWs development into tropical cyclones is mainly due to the presence of dry mid-to-upperlevel air just ahead of the AEW trough. Despite this study, the reason why a particular AEW will develop or not into a tropical cyclone over the north Atlantic requires more investigation.

The main subject examined in this paper is the difference over the African continent and the Eastern Atlantic between a developing AEW and a nondeveloping AEW. We did not consider synoptic disturbances (AEWs) after the genesis of associated cyclones over the Ocean. Thus, we did not deal with the behaviour of the cyclones over the Atlantic ocean. The data (rawinsonde, OLR, NHC Best Track archives, and NCEP/NCAR reanalysis data) and methods used in this study are presented in Section 2. In Section 3, results of a statistical analysis and a composite study comparing AEWs associated or not with cyclones are presented followed by a case study in Section 4 using available rawinsonde data from Dakar, Senegal. Section 5 presents our conclusions.

\section{Data and Methods}

The data used in this study are the NCEP/NCAR daily reanalyses [23] during 15 years (1989-2003) with the aim to obtain a good sample for the composite study. The rawinsonde observations at Dakar station $\left(17.5^{\circ} \mathrm{W}-14.59^{\circ} \mathrm{N}\right)$ are used to validate the composite study done with the NCEP/NCAR reanalyses trough a case study which compares the characteristics of the AEW associated with hurricane Fran to a non-developing AEW during August 1996. 1996 has been chosen because of the availability of rawinsonde data for Dakar station during that year. Upper air measurements data are available at http://www.weather.uwyo.edu/.

Outgoing Longwave Radiation (OLR) data at 2.5 latitude/longitude from the National Oceanic and Atmospheric Administration (NOAA) are used to estimate deep convection [24]. For example, an OLR equal to 220 w.m ${ }^{2}$ could be associated with cloudtop temperature of $-23^{\circ} \mathrm{C}$. In this study, we considered only OLR values weaker than $220 \mathrm{w} . \mathrm{m}^{-2}$ to depict the deep convection. Information about named TCs is provided by The NOAA/National Hurricane Center (NHC) Best Track archives which summarize the dates of occurrence and tracks of North Atlantic TCs.

In this work, only cyclones generated off the West African coast (East of $40^{\circ} \mathrm{W}$ ) and associated with AEWs are studied in order to investigate West African climate features associated with North Atlantic cyclonic activity. A tracking of the maximum cyclonic vortices associated with AEWs troughs and the Wavelet analysis technique are used to show that TCs considered in this study are associated with AEWs. The Wavelet analysis technique described in $[25,26]$ and used by Diedhiou et al. [11] to detect AEWs in NCEP/NCAR and ECMWF reanalyses plots significant energy values of the wavelet relative to a red-noise spectrum. This technique allows us to detect AEWs frequency and temporal localisation. The characteristics of these AEWs are compared to those of AEWs that did not develop into cyclones. The NHC Best Track archives are used to deduce a mean longitude genesis of named TCs $\left(30^{\circ} \mathrm{W}\right)$. The genesis day of TCs is considered to be the first position in the NHC best track (development into a tropical depression).

AEWs not associated with cyclones were detected at this same mean longitude $\left(30^{\circ} \mathrm{W}\right)$ of TCs genesis to have approximately the same time reference as for AEWs with cyclones. We retained these two classes of AEWs and initially carried out a comparative composite study of AEWs associated or not with cyclones with the aim of depicting the main large-scale differences between them. After completing the composite study, we carried out a case study with available observed data (rawinsonde data) from the Dakar station during 1996. We analyse a wave associated with a cyclone (hurricane Fran in August 1996) and a non-developing AEW.

\section{Results}

3.1. Statistical Analysis. A statistical study showed that out of a total of 163 cyclones that occurred throughout the whole tropical North Atlantic Ocean between 1989 and 2003 (a period of 15 years), 48 cyclones generated in the eastern part of the MDR (East of $40^{\circ} \mathrm{W}$ ) are considered in this study. We found that, except for 7 cases, these cyclones had long lifecycles (lifecycle equal or greater than 9 days). The lifecycle is calculated by summing the number of days in which named cyclones are in tropical depression or a stronger stage. Moreover, these cyclones were all associated with AEWs. This is illustrated in Figure 1. AEWs troughs have been tracked from the genesis days of associated cyclones back to West Africa. These tracks are obtained by following the location of maxima of relative vorticity greater or equal to $0.5 \times 10^{-5} \mathrm{~s}^{-1}$ at $850 \mathrm{hPa}$ as in Thorncroft and Hodges [18]. This figure shows that AEWs coming from the southern track as well as from the northern track are involved in cyclonic activity over the North Atlantic. But 40 in 48 cyclones considered in this study are southern AEWs origins suggesting that these AEWs contribute mainly to Atlantic cyclonic activity in coherence with Thorncroft and Hodges [18] studies.

A wavelet analysis is done to confirm that those cyclones considered are associated with AEWs (Figure 2). An example of the wavelet analysis for 1995 summer season is performed (Figure 2(a)) by considering the meridional wind field at $700 \mathrm{hPa}$ over a domain east of the mean longitude of cyclone genesis $\left(30^{\circ} \mathrm{W}-15^{\circ} \mathrm{W}, 5^{\circ} \mathrm{N}-15^{\circ} \mathrm{N}\right)$. This latitude band $\left(5^{\circ} \mathrm{N}-\right.$ $15^{\circ} \mathrm{N}$ ) encompasses mainly the southern track of AEWs in coherence with the results of Figure 1. Except cyclone 


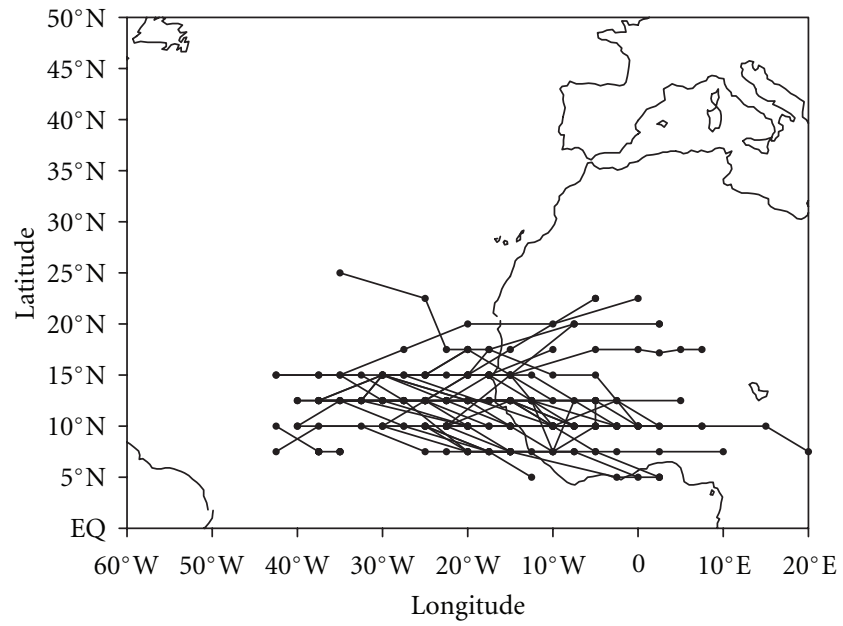

Figure 1: Tracks of all AEWs associated with cyclones (48 developing AEWs). These tracks are obtained by following the maxima of relative vorticity at $850 \mathrm{hPa}$ associated with AEWs troughs. For each cyclone, maximum of relative vorticity is tracked from the genesis day of the cyclone to Africa until this value is less than $0.5 \times 10^{-5} \mathrm{~s}^{-1}$. Genesis dates of cyclones are obtained from the NHC Best Track.

Pablo (4 October), all the cyclones were associated with a significant maximum energy in the mean 3-5-day band periods of the wavelet analysis. We verified that the short lifecycle of cyclone Pablo is due to high values of vertical wind shear over the North Atlantic which are known to be unfavourable for cyclonic activity. This figure also confirms that the 3-5-day AEWs occurred mainly during the rainy season in West Africa and tropical North Atlantic while the 6-9-day AEWs occurred mainly at the beginning and at the end of the rainy season [11].

Figure 2(b) shows the results of a composite study of all the TCs that occurred from 1989 to 2003 over the same domain. The average modulus over this domain in the 3-5day band period of the wavelet analyses of the meridional wind at $700 \mathrm{hPa}$ is at its maximum at the genesis day $(t=0)$. Genesis days of named cyclones are provided by the NHC and correspond to the first position in the NHC Best Track archives. The composite of developing AEWs is made by considering the average of 3 days before the genesis days of cyclones (from $t-3$ to $t-1$ ) to focus only on AEWs characteristics during their propagation from the continent to the Eastern Atlantic Ocean and before the genesis of associated cyclones.

Non-developing AEWs are detected using the same method as the previous case at the mean longitude genesis of cyclones $\left(30^{\circ} \mathrm{W}\right)$. Dates associated with a strong energy level in the wavelet analysis and a maximum relative vorticity at $850 \mathrm{hPa}$ are considered to be affected by AEWs. An Illustration of the composite structure of non-developing AEWs is shown in Figure 3 representing the westward propagation over West Africa of associated streamlines at $700 \mathrm{hPa}$ with a succession of troughs and ridges. The phase speed and the wavelength of the AEWs are, respectively, around $8 \mathrm{~m} / \mathrm{s}$ and $3000 \mathrm{~km}$, within the ranges reported in previous investigations [8]. The composite of developing

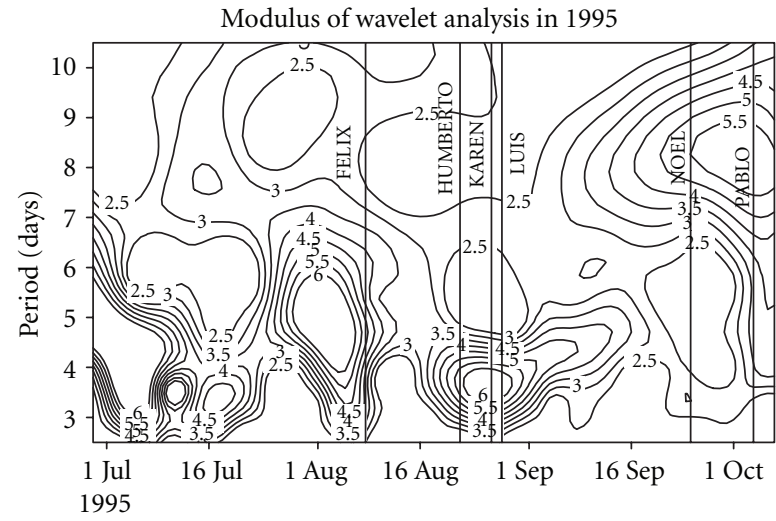

(a)

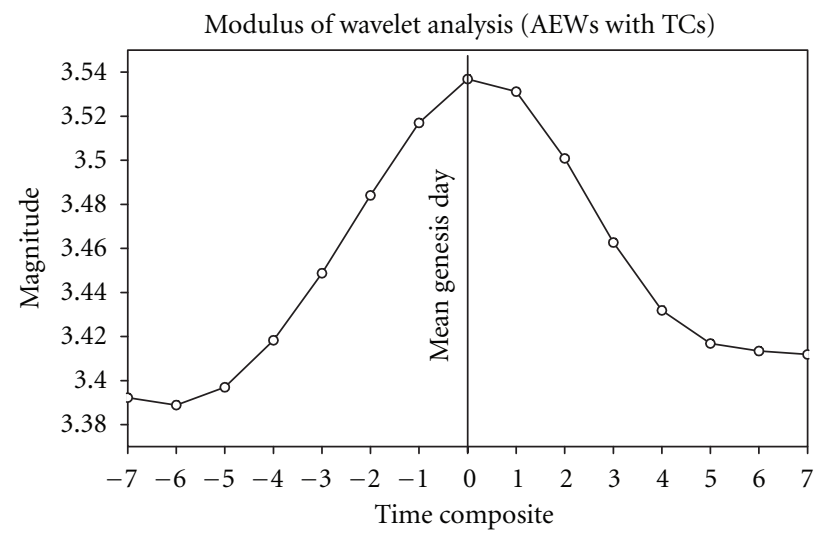

(b)

FIGURE 2: Modulus of the wavelet analysis on the meridional wind at $700 \mathrm{hPa}$ (a) in 1995 over the domain $\left(27.5^{\circ} \mathrm{W}-15^{\circ} \mathrm{W}, 5^{\circ} \mathrm{N}-\right.$ $\left.17.5^{\circ} \mathrm{N}\right)$. The line represents the mean genesis days of cyclones obtained from the Best Track of NHC. Modulus of the wavelet analysis in the 3-5-day band periods ( $t=0$ corresponds to the mean genesis day from NHC archives) performed over the domain $\left(27.5^{\circ} \mathrm{W}-15^{\circ} \mathrm{W}, 5^{\circ} \mathrm{N}-17.5^{\circ} \mathrm{N}\right)$ for AEWs associated with cyclones (b).

AEWs is made by considering the average of 3 days (from $t-3$ to $t-1)$ before the day of their detection at the mean longitude genesis of cyclones $\left(30^{\circ} \mathrm{W}\right)$. Thus, in each case, an average over 3 days of 48 AEWs is considered.

3.2. Composite Study. This section presents the results of a composite study done with 48 AEWs that developed into cyclones and 48 AEWs that did not over the Eastern Atlantic in the 1989-2003 period.

The meridional gradient of potential vorticity $(\mathrm{PV})$ on $315 \mathrm{~K}$ isentropic surface (near $700 \mathrm{hPa}$ or $3 \mathrm{~km}$ ) is computed to help define the areas of barotropic and baroclinic instabilities which are the processes involved in waves genesis and intensification. AEWs are associated with a strong signal at this level $(315 \mathrm{~K})$. This level $(315 \mathrm{~K})$ intersects the AEJ over West Africa [27, 28]. Burpee [8] found that the meridional gradient of $\mathrm{PV}$ changes sign over Africa at the mid-troposphere (near $700 \mathrm{hPa}$ ). This sign reversal of meridional gradient of PV satisfies a necessary condition for the barotropic-baroclinic instability of the mean flow [29], 


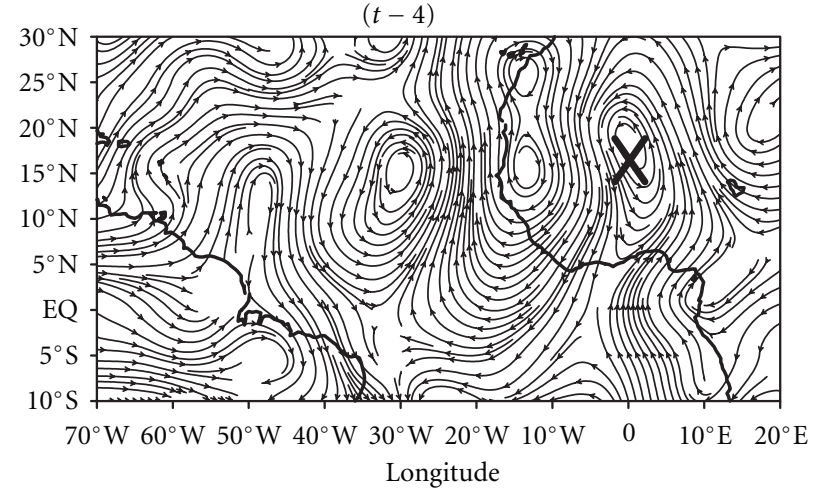

(a)

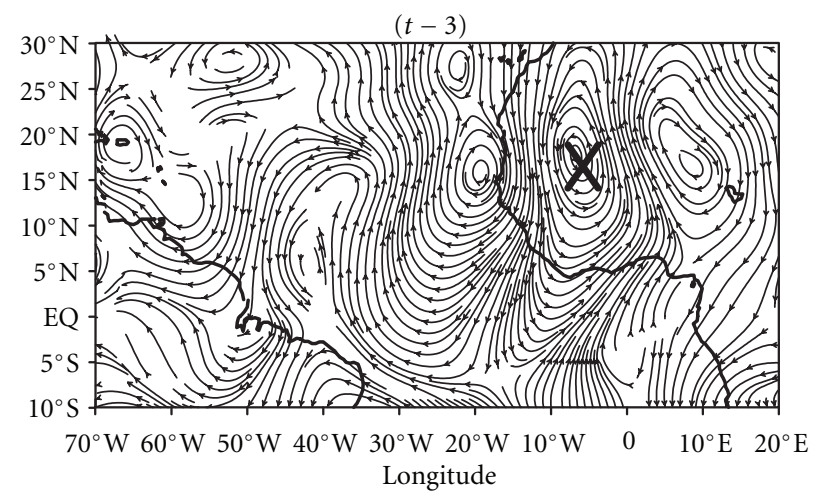

(c)

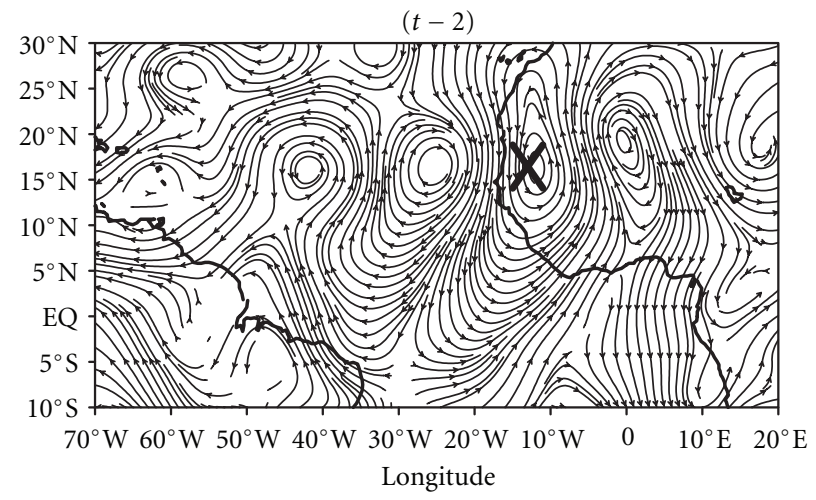

(e)

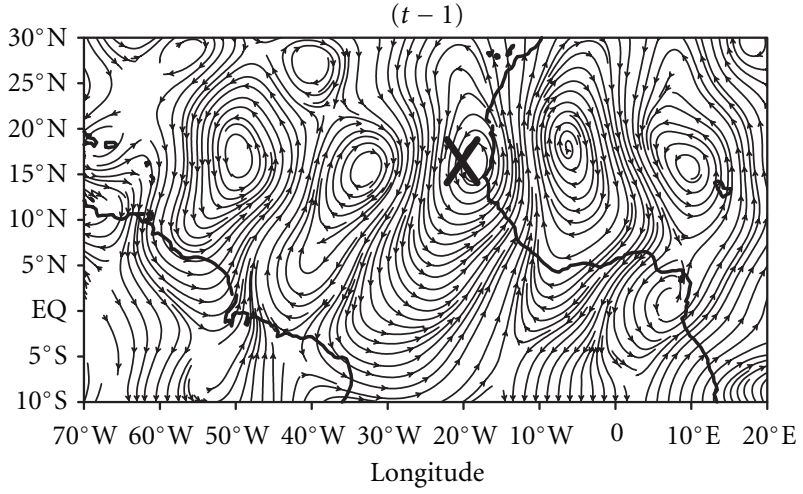

(b)

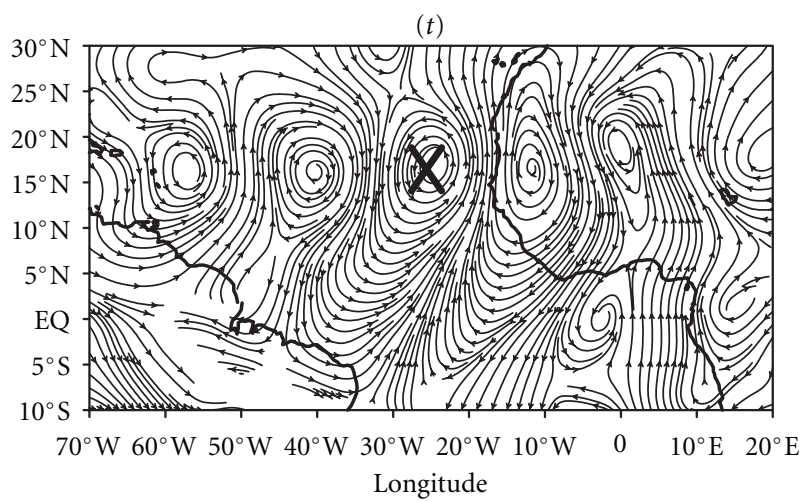

(d)

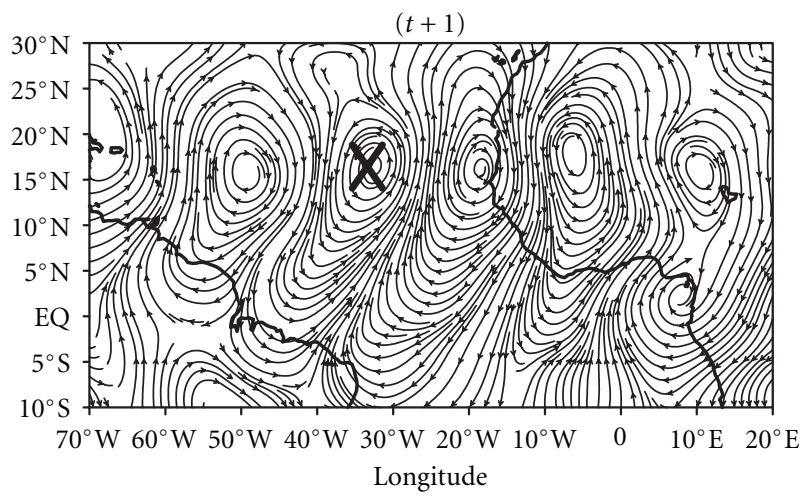

(f)

FIgURE 3: Streamlines at $700 \mathrm{hPa}$ for the $48 \mathrm{AEWs}$ not associated with cyclones. The time sequence $(t-4, t+1)$ considered in this study is from 4 days before to 1 days after the detection of AEWs at the mean genesis longitude for the 48 cyclones $\left(30^{\circ} \mathrm{W}\right)$. T represents the detection time of AEWs at this mean longitude. $X$ represents the location of AEWs axis.

areas where there is a negative meridional gradient of $\mathrm{PV}$ $(\partial \mathbf{P V} / \partial \mathbf{y})$ are favorable to the growth of AEWs [30]. The result of observational studies by Norquist et al. [31] and idealized modelling simulations by Thorncroft and Hoskins $[27,32]$ have shown that both baroclinic and barotropic processes contribute to the growth of AEWs. Potential Vorticity is calculated on $315 \mathrm{~K}$ isentropic surface (near $700 \mathrm{hPa}$ ) following methods described by Molinari et al. [33] using:

$$
\mathrm{PV}=g \sigma^{-1}\left(\zeta_{\theta}+f\right)
$$

where $\sigma=-(\partial p / \partial \theta)$ and $f=2 \omega \sin (\varphi), \theta$ is potential temperature, $f$ is the Coriolis force, $\omega$ is the angular velocity of the earth, $\varphi$ is the latitude, and $\zeta_{\theta}$ represents the vertical component of relative vorticity computed on an isentropic surface. According to Dickinson and Molinari [28], the sign reversal is the result of the existence of high values of PV in the cyclonic shear zone near the southern flank of the $\mathrm{AEJ}$ and from the presence of PV values close to zero over the desert regions of North Africa in the lower troposphere near the northern flank of AEJ. These low values of PV over the Sahara are consistent with the presence of a deep mixed 

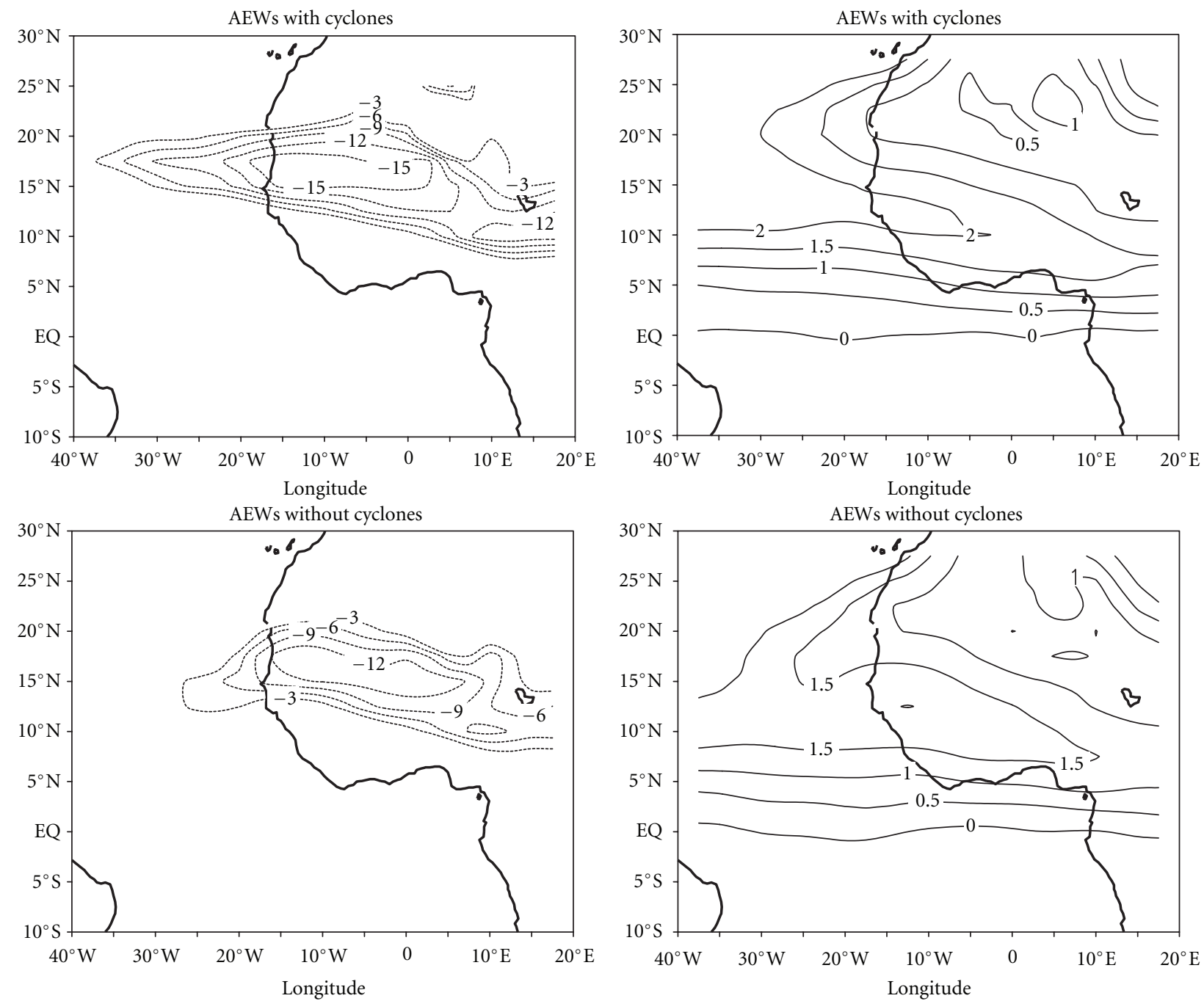

Figure 4: Meridional gradient of Potential Vorticity (left) and Potential Vorticity (right) at 315-K isentropic surface for AEWs associated with cyclones (top) and for non-developing AEWs (AEWs not associated with cyclones (bottom)). Units are PVU for the PV and 0, $01 \mathrm{PVU} / 100 \mathrm{~km}$ for the meridional gradient of PV. $1 \mathrm{PVU}=10^{-7} \mathrm{~m}^{2} \mathrm{~K} \mathrm{~s}^{-1} \mathrm{~kg}^{-1}$.

layer over this region creating almost zero static stability $(\partial \theta / \partial p) \approx 0$ in the lower troposphere $[28,34]$.

Figure 4 shows that developing AEWs are associated with a greater meridional gradient of $\mathrm{PV}$ in the areas of negative values. These larger negative values are found to extend further into the North Atlantic Ocean. Thus, AEWs that develop into cyclones are associated with the strongest baroclinic and barotropic conversions suggesting that these disturbances may be stronger than the nondeveloping AEWs. This result is confirmed by the Potential vorticity structure itself which shows larger values in the developing AEWs case suggesting that these perturbations are the strongest. This result is consistent with the studies of Landsea and Gray [35] who hypothesized that on an interannual time scale, strong cyclonic activity is associated with the propagation in the North Atlantic Ocean of a large number of AEWs with strong amplitude emanating from Africa.
The horizontal and vertical shears of the zonal wind at mid-levels are known to be important for the growth of AEWs and are dynamically related to barotropic and baroclinic instabilities $[8,36]$. The relative contribution of these two processes in the growth of developing and nondeveloping AEWs is computed. Figure 5 shows that the meridional gradient of zonal wind at $700 \mathrm{hPa}$ (horizontal shear) presents stronger negative values in the case of developing AEWs suggesting that horizontal wind shear at midlevels is greater in the case of developing AEWs. But the vertical wind shear at mid-levels (difference between zonal wind at $700 \mathrm{hPa}$ and $600 \mathrm{hPa}$ ) does not present any systematic difference between these two types of AEWs (figure not shown). Therefore, horizontal shear may be the dominant process which explains the greatest instability of the AEJ in the case of developing AEWs.

Low values of the total vertical wind (zonal and meridional wind) shear between low-levels $(850 \mathrm{hPa})$ and upper 


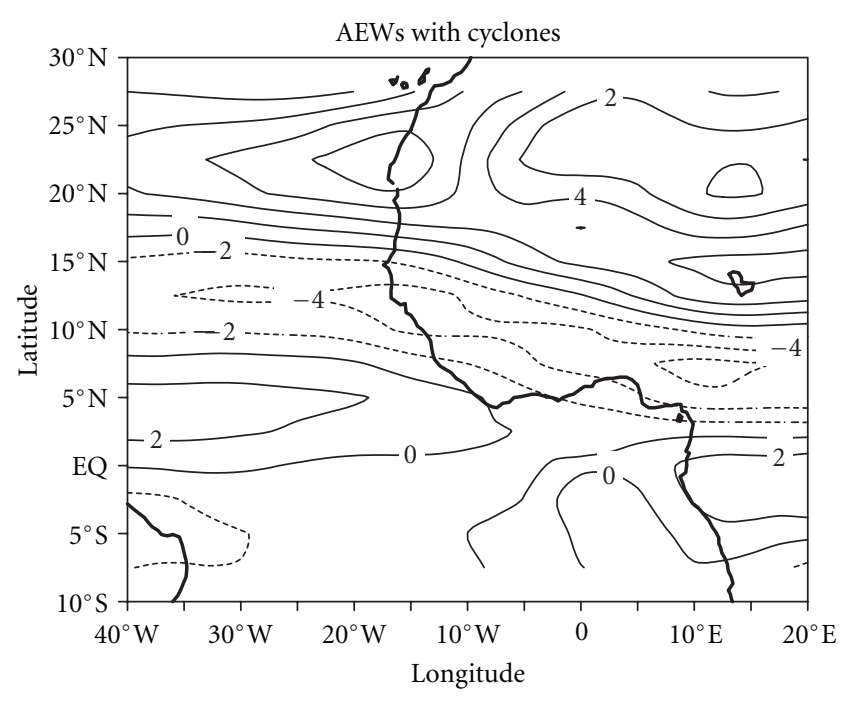

(a)

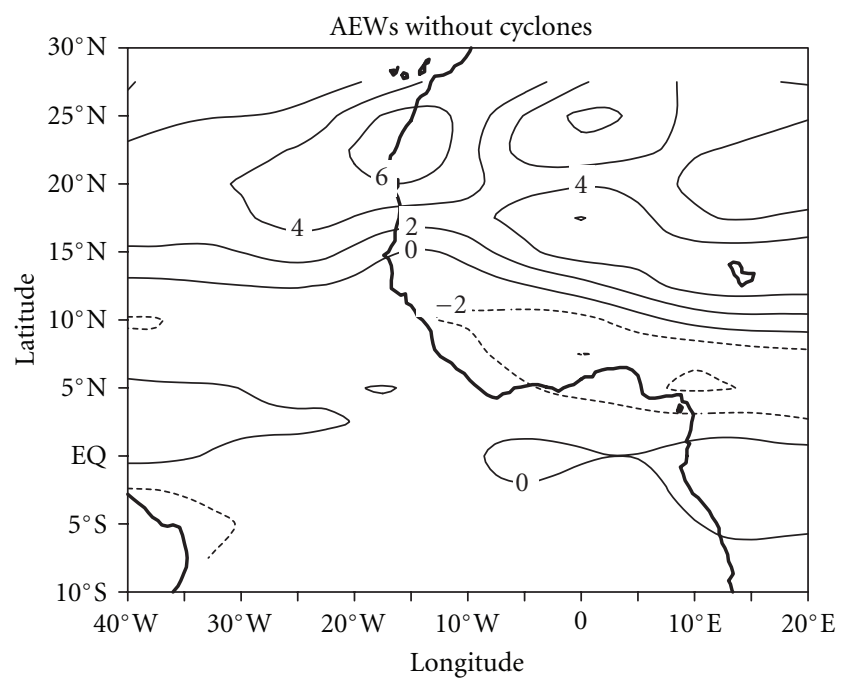

(b)

FIgURE 5: Horizontal shear of zonal wind at $700 \mathrm{hPa}$ for AEWs associated with cyclones (a) and for non-developing AEWs (b). Unit is $10^{-6} \mathrm{~s}^{-1}$.

levels $(200 \mathrm{hPa})$ are known to be favorable for cyclonic activity $[1,2]$. Lower values of vertical wind shear are present over Africa and the Eastern Atlantic for developing AEWs suggesting the existence of an environment dynamically favourable for deep convection (figure not shown).

The Vorticity analyses depict the relative strength of AEWs in both cases. Figure 6 shows that the mean relative vorticity at $850 \mathrm{hPa}$ is greater for developing AEWs $\left(9.10^{-6} \mathrm{~s}^{-1}\right)$ than for non-developing AEWs over the continent and over the ocean, consistent with the PV study. Therefore, this result confirms that the developing AEWs case is characterized by the existence of strong AEWs propagating in the North Atlantic Ocean consistent with the findings of Landsea and Gray [37]. Given sufficient amplitude, these AEWs are more likely to initiate cyclogenesis $[18,38]$. Over North Africa (Sahara desert), positive values of relative

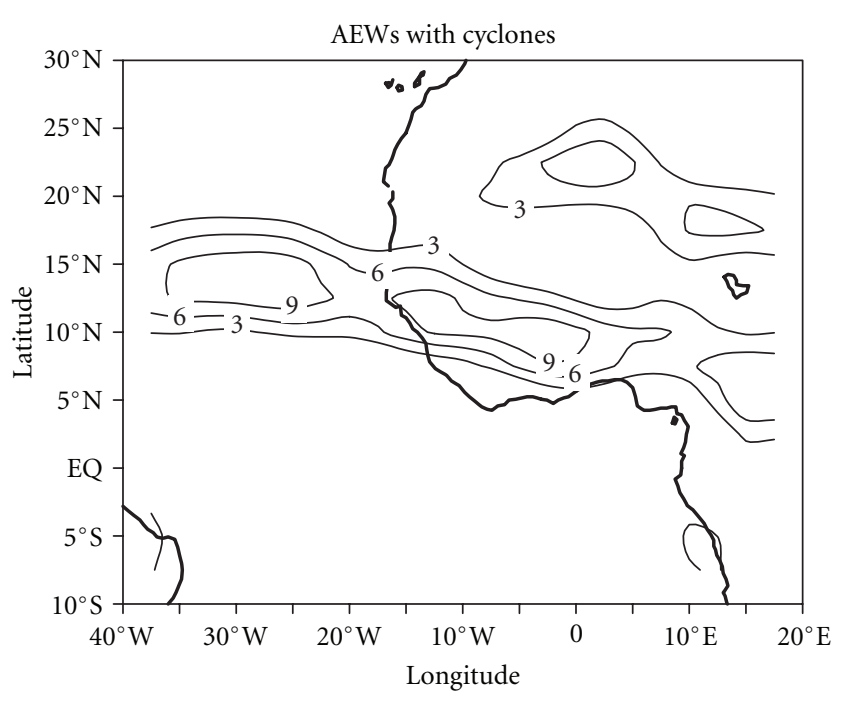

(a)

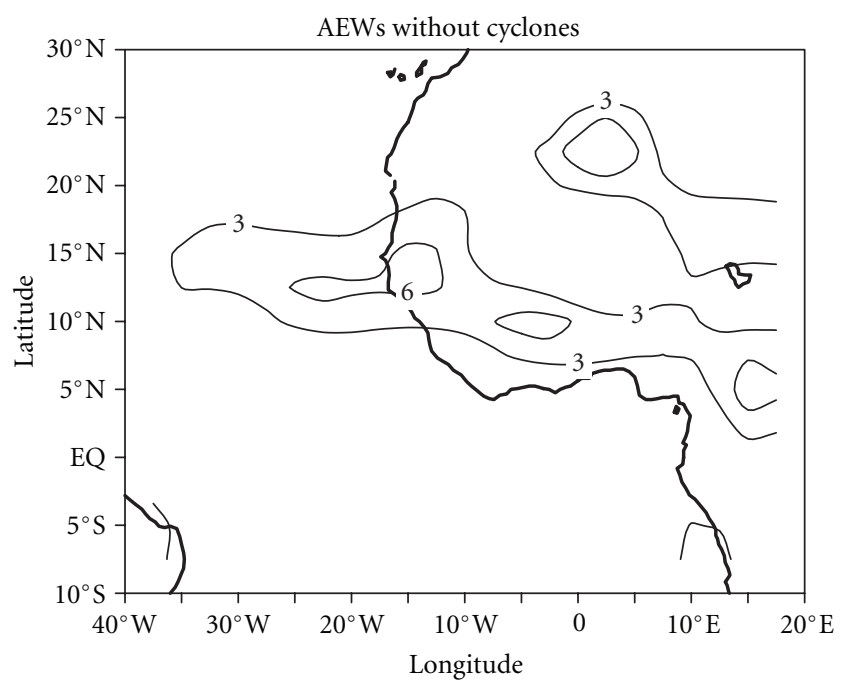

(b)

Figure 6: Relative Vorticity at $850 \mathrm{hPa}$ for AEWs associated with cyclones (a) and for non-developing AEWs (b). Only values greater than or equal to zero are contoured. Unit is $10^{-6} \mathrm{~s}^{-1}$.

vorticity, which are related to the northern track of AEWs, do not show any systematic difference between these two types of AEWs.

After diagnosing the difference between these two types of AEWs using dynamical parameters, the mean state of the atmosphere is assessed using thermodynamic parameters such as the Potential of convection (Pc) also called the potential of instability. The $\mathrm{Pc}$ is the difference between the equivalent potential temperature at $1000 \mathrm{hPa}$ (surface) and $500 \mathrm{hPa}$ (mid-troposphere) following Gray [2]:

$$
\mathrm{Pc}=\theta_{e}(1000)-\theta_{e}(500) \text {, }
$$

where $\theta_{e}$ is the equivalent potential temperature.

The Potential of convection is a good parameter for studying the degree of the atmospheric instability. The 


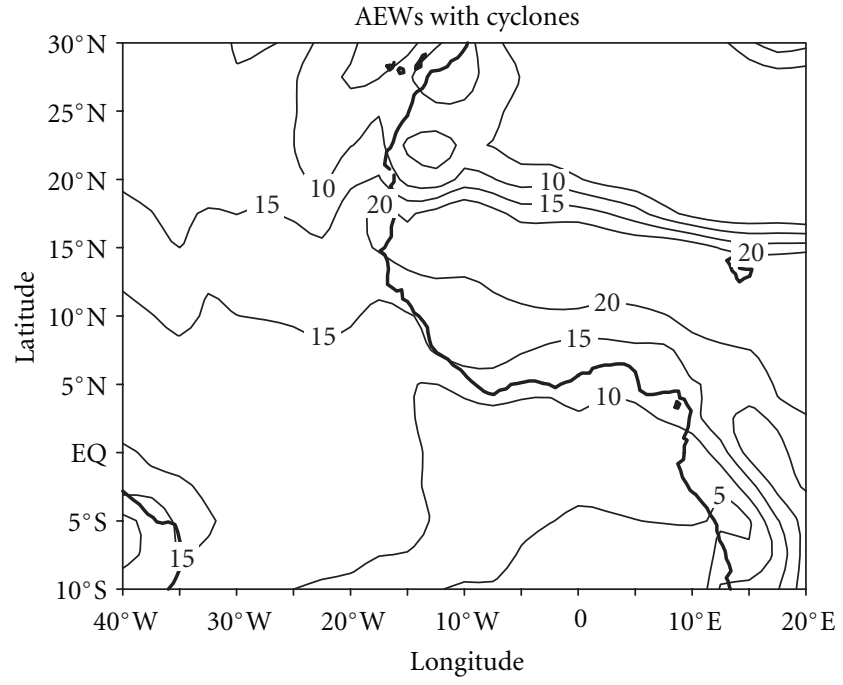

(a)

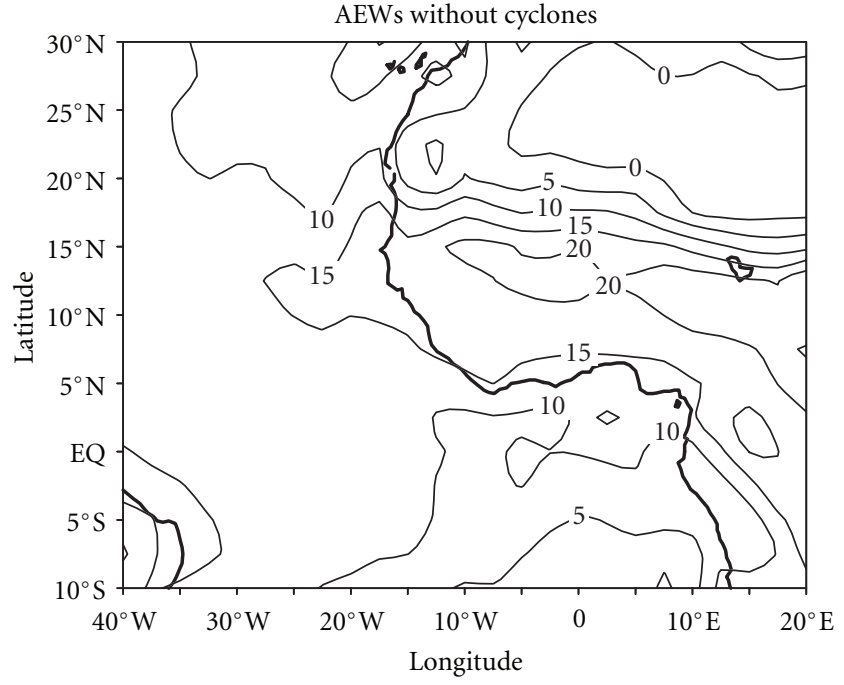

(b)

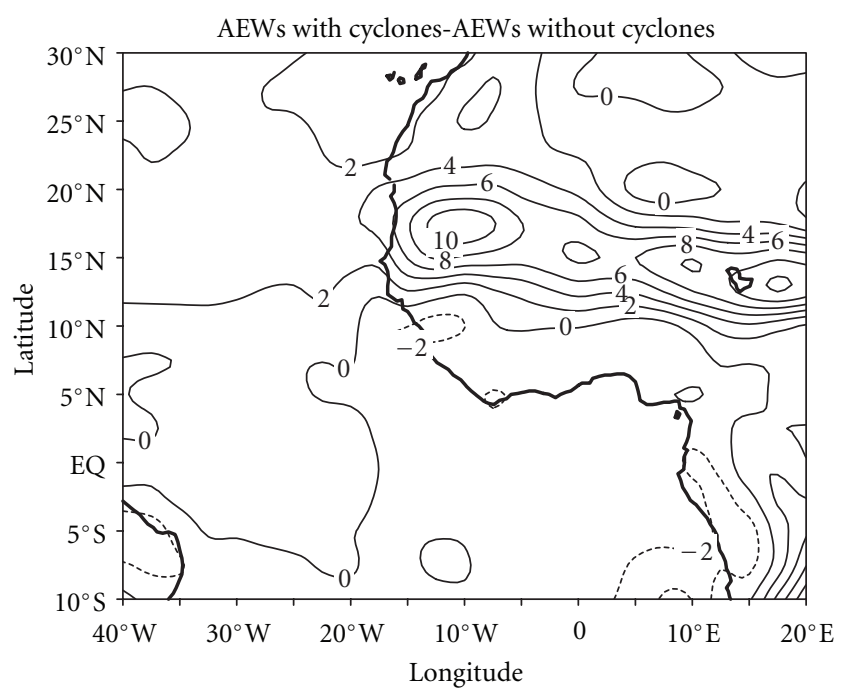

(c)

Figure 7: Potential of convection (K) for AEWs associated with cyclones (a), for non-developing AEWs (b) and the difference between AEWs associated with cyclones and non-developing AEWs (c).

highest values of the Pc were found for developing AEWs (as high as $24 \mathrm{~K}$ ). The difference in Pc between developing and non-developing AEWs shows an axis of maximum positive values along $15^{\circ} \mathrm{N}$ (Figure 7). This axis extends well into the North Atlantic Ocean, indicating that the atmosphere is more potentially unstable for the cases of developing AEWs. This northward shift in the peak in Pc for developing AEWs corresponds to a general northward shift in the monsoon trough. We verified that this greater instability is associated with the presence of a monsoon layer deeper in latitude and more intense in magnitude (figure not shown). This is coherent with the results of Newell and Kidson [39] suggesting that intense AEWs are associated with a wetter monsoon phase. NOAA Outgoing Longwave Radiation (OLR) data exhibit lower values over Africa for developing AEWs suggesting the presence of a deeper convection and a northward shift of the Inter Tropical
Convergence Zone (not shown). Moreover, this strong ITCZ is located in a region characterized by a high humidity in the mid-levels which is favourable for the maintenance of a deeper convection for the developing AEWs.

This result is consistent with the mean August-October anomaly of geopotential height at $850 \mathrm{hPa}$ computed from 1989 to 2003 between AEWs associated with and without cyclone (Figure 8). Negative values of the geopotential field indicate the existence of a lower pressure while positive values are associated with a relatively higher pressure situation relatively to the basic state. AEWs that developed into cyclones are characterized by the existence of lower pressure over Western Africa and the North Atlantic Ocean than the nondeveloping case. This result is consistent with the presence of intense AEWs in the developing case. It also suggests that a more favourable environment for tropical cyclogenesis exist for developing AEWs. Non-developing 


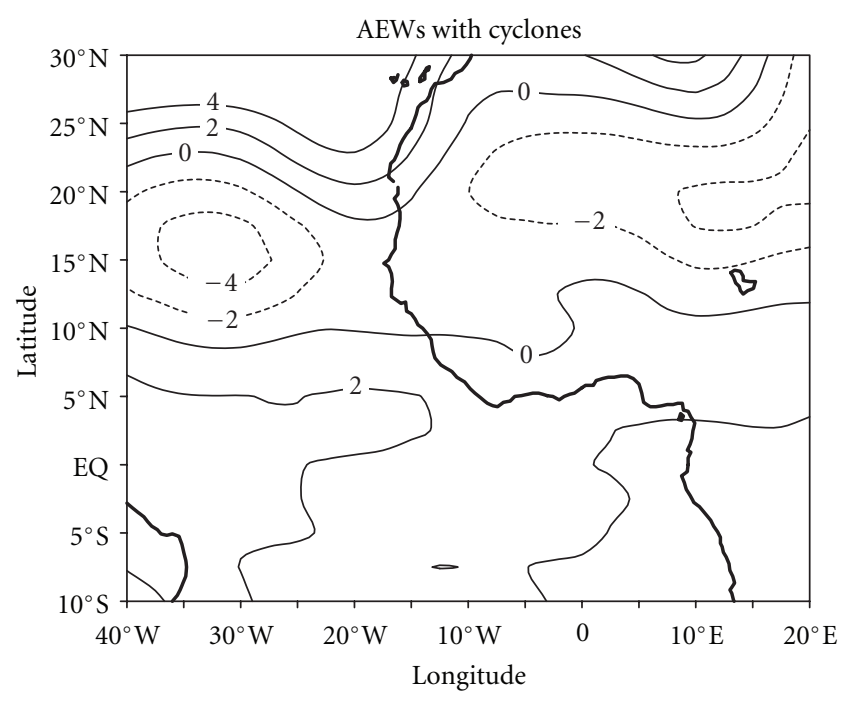

(a)

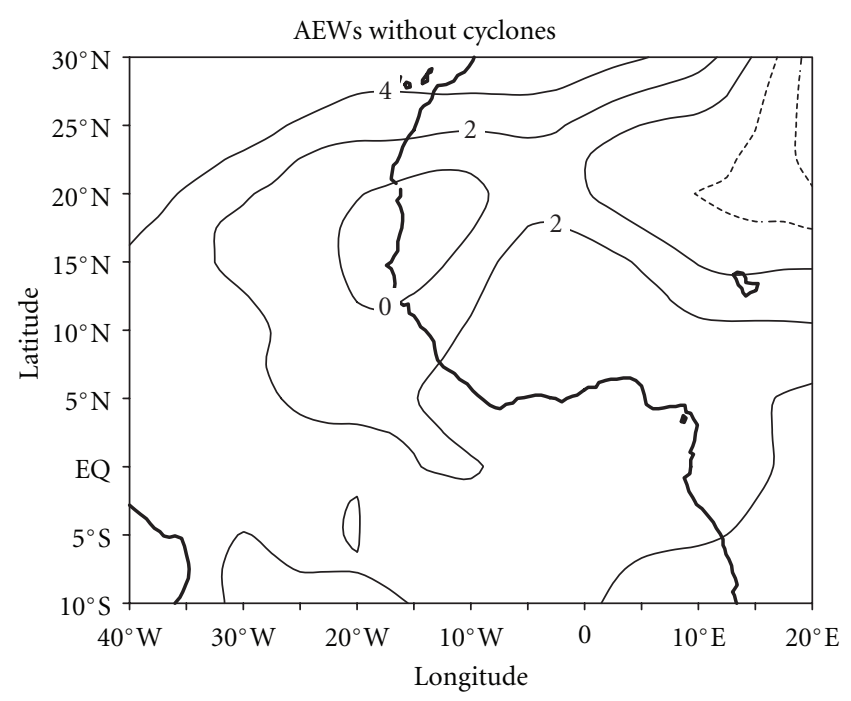

(b)

Figure 8: Anomaly of geopotential height at $850 \mathrm{hPa}$ from the mean August-October 1989-2003 (m) for AEWs associated with cyclones (a) and for non-developing AEWs (b).

AEWs appear to be linked to more stable conditions in the eastern North Atlantic.

\section{Case Study}

This section presents case study results of two strong AEWs that occurred during August 1996. The case of 10-13 August 1996, representing a non-developing AEW, is compared to the case 21-22 August 1996, representing the AEW associated with Hurricane Fran (developing AEW) initiated on 23 August 1996 close to the West African coast.

Hurricane Fran formed from a tropical AEW that emerged from the West coast of Africa on 22 August. Fran was a Cape Verde hurricane (these are cyclones that developed into TCs fairly close to the Cape Verde Islands typically in August and September) that moved across the North Atlantic Ocean during the peak of the hurricane season. Fran made landfall on the North Carolina coast as a category three hurricane (major hurricane) on the Saffir/Simpson Hurricane Scale and produced significant storm surge flooding on the North Carolina coast, widespread wind damage over North Carolina, and Virginia, and extensive flooding from the Carolina to Pennsylvania (USA). According to Associated Press reports, Hurricane Fran was responsible for 34 deaths. Most of the deaths were caused by flash flooding in the United States (http://www.nhc.noaa.gov/).

Streamlines associated with the wind field at $700 \mathrm{hPa}$ from NCEP/NCAR reanalyses during a time sequence of 3 days for two cases of AEWs are shown in Figure 9. The westward propagation of a well-defined AEW characterized by a succession of a trough and a ridge is visible during these two time sequences: the successive positions of the trough for the non-developing AEW are $5^{\circ} \mathrm{W}$ (10 August), $12.5^{\circ} \mathrm{W}$ (11 August), and $20^{\circ} \mathrm{W}$ (12 August) and for the AEW associated with the hurricane Fran, they are $5^{\circ} \mathrm{W}$ (21 August), $15^{\circ} \mathrm{W}(22$ August), and $20^{\circ} \mathrm{W}$ (23 August).

Outgoing Longwave radiation has been used to understand the characteristics of the convection during the propagation of these two contrasting AEWs (Figure 10). The developing AEW is accompanied by lower values of OLR suggesting the presence of a deeper convection in that case than for the non-developing AEW. An intensification and a westward propagation of the developing AEW from the West African coast to the Eastern Atlantic is noted from august 22nd 1996 to august 23rd 1996 consistent with the genesis of the Hurricane Fran on the 23rd of August 1996 over that region $\left(21^{\circ} \mathrm{W}, 14^{\circ} \mathrm{N}\right)$. The reduced convection found in the non-developing case is in line with Hopsch et al. [22] studies.

The radiosounding of Dakar station $\left(17.5^{\circ} \mathrm{W}, 15^{\circ} \mathrm{N}\right)$ has been used to further study the difference between AEWs that develop in cyclones than the ones that did not. The Mean time series of humidity between low and mid-levels and of temperature over the low-levels of the atmosphere in August 1996 (Figure 11) shows that the AEW associated with the hurricane Fran (F) is characterized by higher humidity and cooler temperatures than the non-developing AEW (W). The temperature and the humidity are, respectively, $85 \%$ and $13^{\circ} \mathrm{C}$ in the northerly sector of the AEW associated with a cyclone. The relative humidity is also higher at mid to high levels in the northern sector of the AEW associated with Hurricane Fran (figure not shown). This result is consistent with Hopsch et al. [22] studies who found less humidity at mid to high levels ahead of waves that did not developed into cyclones. Moisture is known to be crucial for the development and maintenance of deep convection $[1,2]$. This result suggests that the environment of the nondeveloping AEW was less conducive to strong convective development.

OLR data showed a westward propagating convective signature for the AEW associated with cyclone Fran. This strong convection is consistent with the presence of stronger humidity in low to middle layers and the cooling of low level temperatures in the case of the AEW that developed into hurricane Fran (F). This cooling may be due to the 

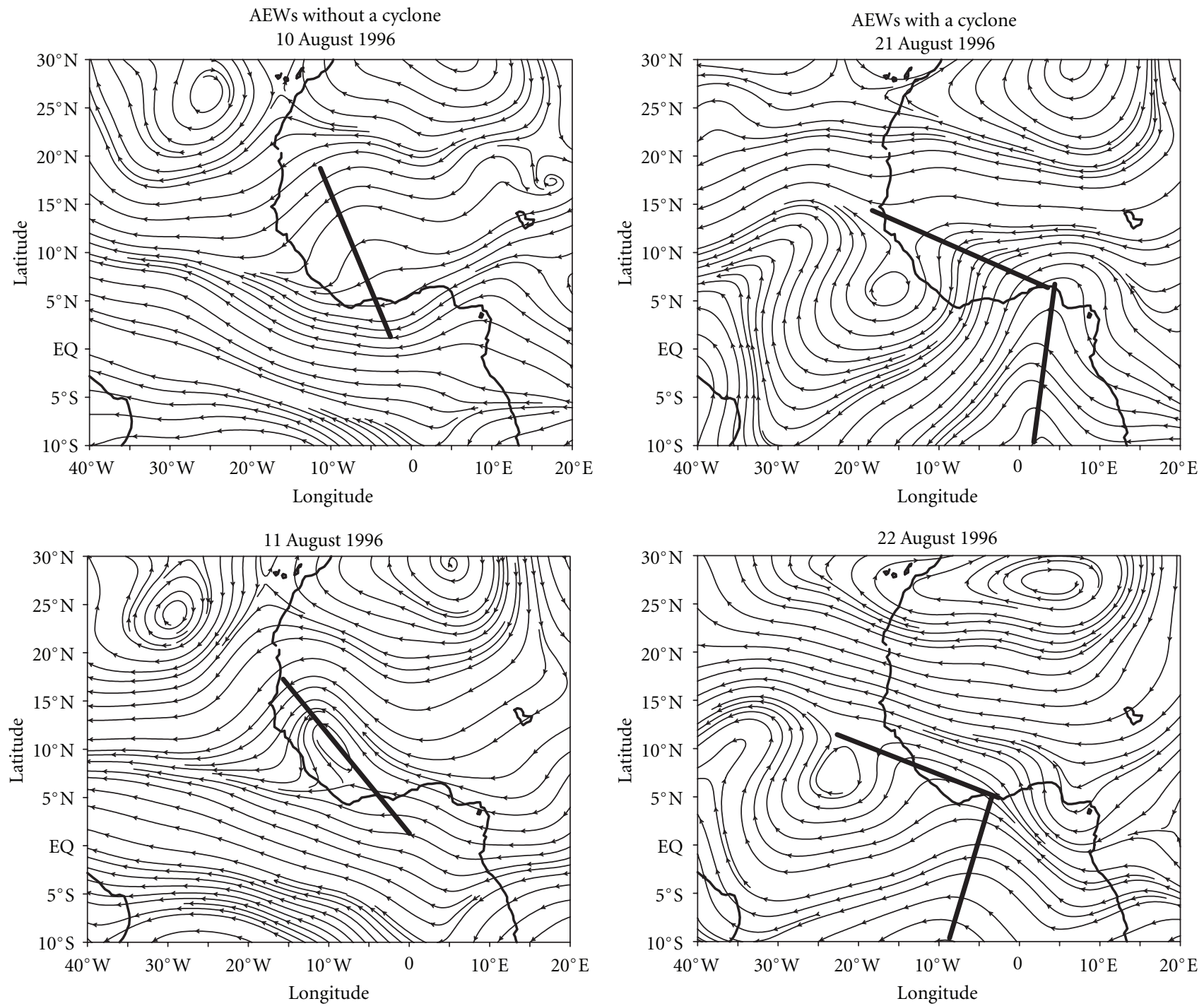

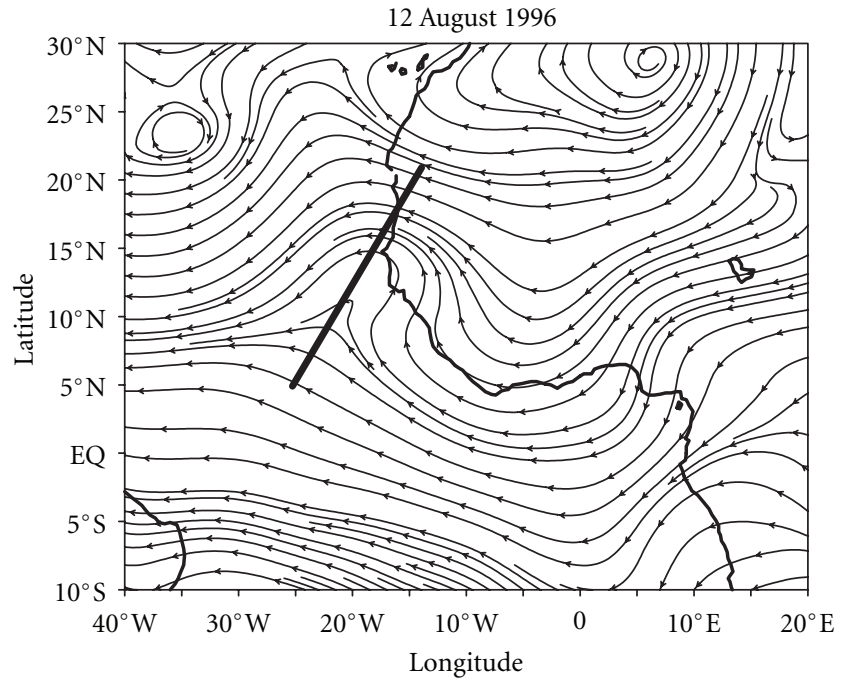

(a)

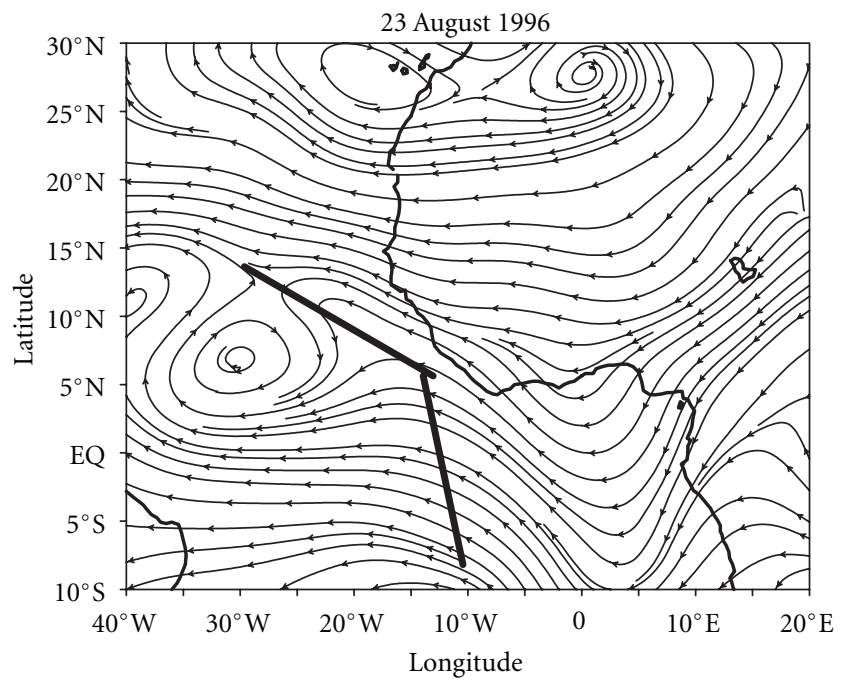

(b)

FigurE 9: Streamlines of the $700 \mathrm{hPa}$ wind for (a) the non-developing AEW (10-12 August 1996) and for (b) the AEW associated with a cyclone (21-23 August 1996). The line represents the location of the trough. 

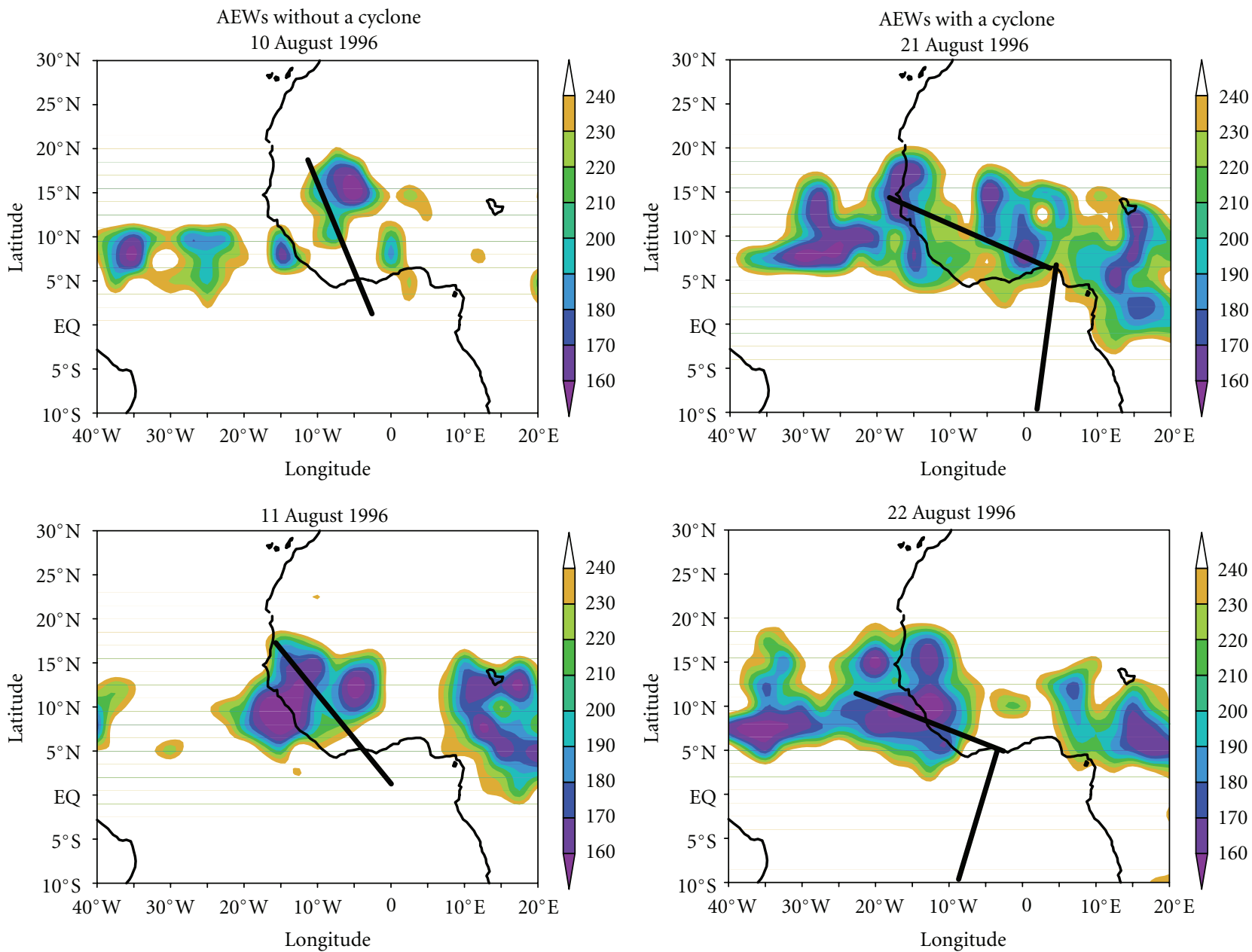

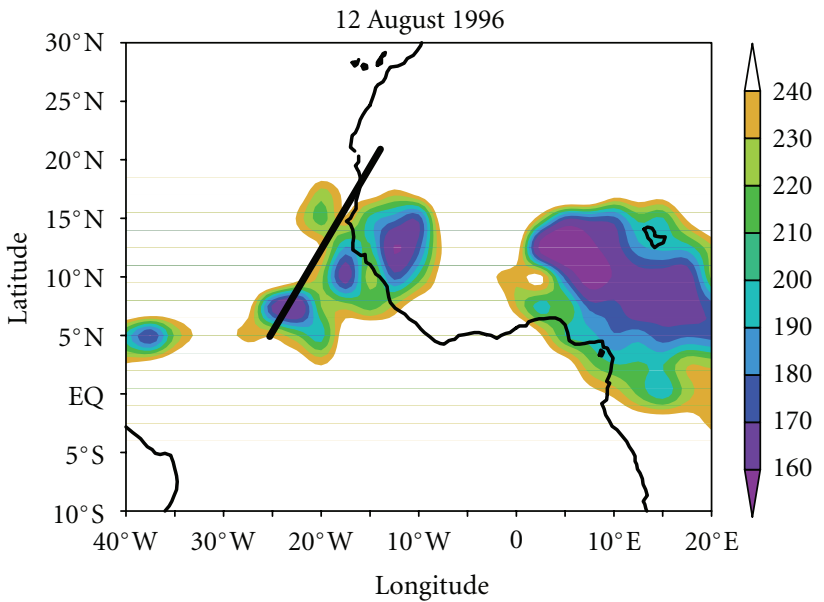

(a)

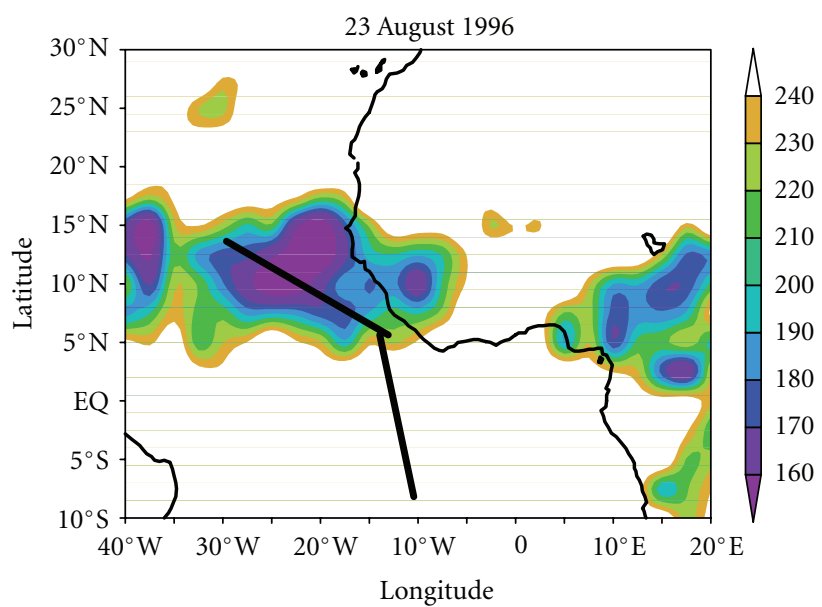

(b)

FIGURE 10: Outgoing Longwave radiation (OLR) for (a) the non-developing AEW (10-13 August 1996) and for (b) the AEW associated with a cyclone (20-23 August 1996). The line represents the location of the trough.

cold downdrafts. Moreover, a westward propagating high humidity is noticed in the developing AEW case when considering NCEP/NCAR reanalysis (figure not shown). Reanalyses wind fields also show the propagation of stronger low level vortices along with a upper level anticyclone leaving the West African coast on August 22 (figure not shown). The possible link between the non-developing AEW and a Saharan air Layer (SAL) event have been studied in order to better understand the factors that may prevent it to develop into cyclones. The SAL is a warm, dry, and often dusty 


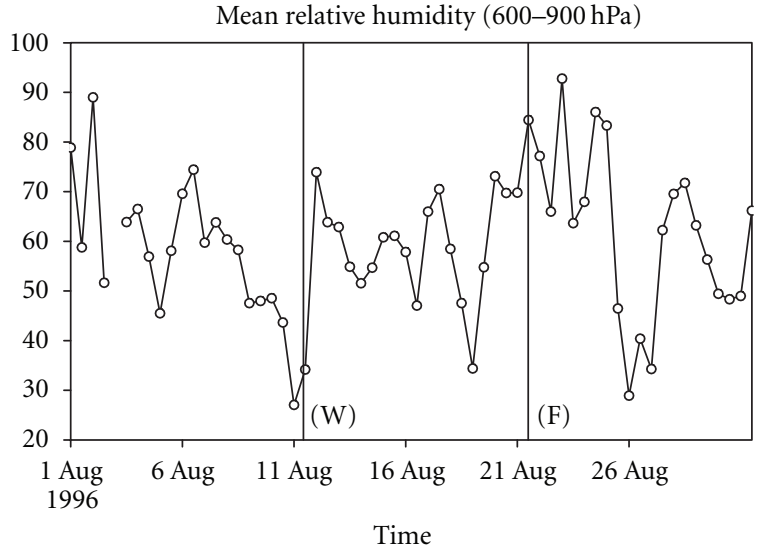

(a)

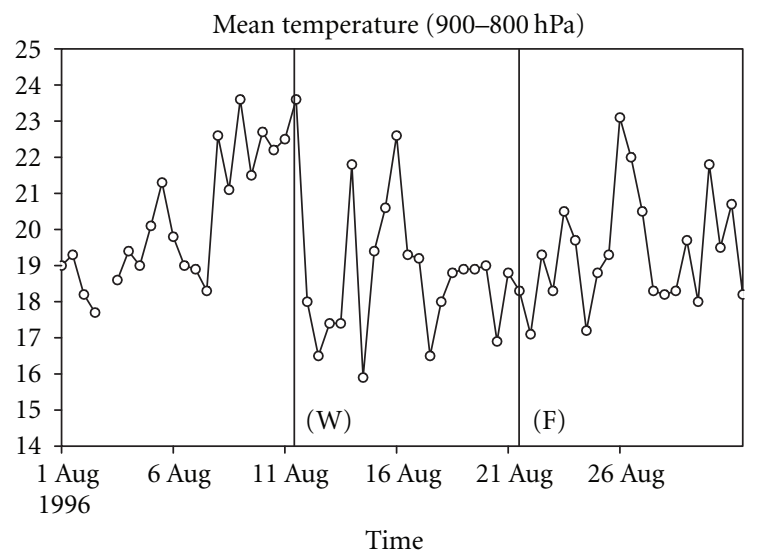

(b)

Figure 11: Mean time series of humidity between low and midlevels (a) and of temperature over the low-levels (b) of the atmosphere in August 1996. The lines represent the passage of the non-developing AEW (W) and the AEW associated with Fran (F) troughs over Dakar station.

air mass visible from the space that propagates from the Saharan desert westward across the Atlantic Ocean and reaches as far as Florida and the Caribbean [40, 41]. The SAL is an important meteorological feature over West Africa and the Atlantic Ocean during the boreal summer [42]. The analysis of the rawinsonde data of Dakar when the trough of the non-developing AEW is over Dakar on August 11 at $00 \mathrm{Z}$ and $12 \mathrm{Z}$ (Figure 12(a)) shows the presence of a temperature inversion associated with a decrease of the humidity at $00 \mathrm{Z}$. At $12 \mathrm{Z}$, the temperature increases by $3.2^{\circ} \mathrm{C}$ in the inversion layer (between $925 \mathrm{hPa}$ and $850 \mathrm{hPa}$ ), and it is still associated with a decrease of the humidity. Using the Total Ozone Mapping Spectrometer (TOMS) aerosol index (http://toms.gsfc.nasa.gov/), we noticed the presence of dust over Dakar on August 11 (figure not shown) confirming the occurrence of a SAL event. This SAL event may induce thermodynamic stability that may play a role in the nondevelopment of that AEW into a cyclone off the West African coast.

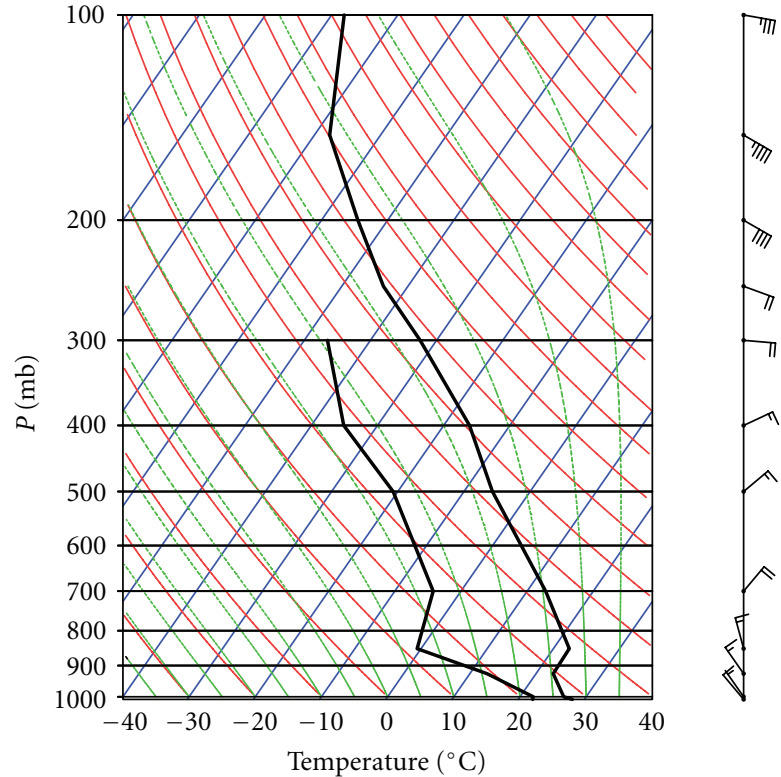

(a)

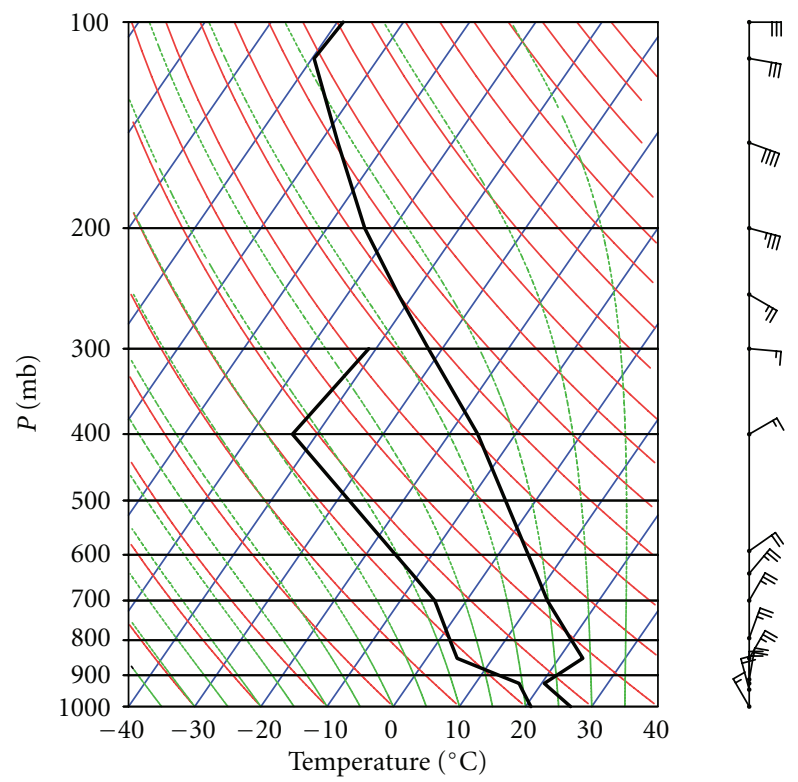

(b)

FIgURE 12: Skew- $T$ plot of rawinsonde data at Dakar on August 11 at $00 \mathrm{Z}$ (a) and $12 \mathrm{Z}$ (b).

In order to go further in the characterization of the degree of conditional instability of these two AEWs, two instability indexes were computed: the Convective Available Potential Energy (CAPE) and the Convective Inhibition (CIN). The CIN is the energy needed to lift an air parcel vertically and pseudoadiabatically from its originating level to its level of free convection (LFC).

$$
\mathrm{CIN}=\int_{p_{s}}^{\mathrm{LFC}}\left(T_{v a}-T_{v}\right) \cdot R a \cdot d(\ln (P)) .
$$


TABLE 1: CAPE and CIN values in the case of the AEW associated with a cyclone (a) and in the case of the non-developing AEW (b) over land, over the coast, and over the ocean.

(a) AEW with a cyclone.

\begin{tabular}{lccc}
\hline Domain & Land $\left(10^{\circ} \mathrm{N}, 5^{\circ} \mathrm{E}\right)$ & Coast $\left(15^{\circ} \mathrm{N}, 17^{\circ} \mathrm{W}\right)$ & Ocean $\left(15^{\circ} \mathrm{N}, 25^{\circ} \mathrm{W}\right)$ \\
\hline $\mathrm{CAPE}(\mathrm{J} / \mathrm{kg})$ & 787 & 1228 & 1251 \\
$\mathrm{CIN}(\mathrm{J} / \mathrm{kg})$ & 74 & 13 & 0 \\
\hline
\end{tabular}

(b) Non-developing AEW.

\begin{tabular}{lccc}
\hline Domain & Land $\left(10^{\circ} \mathrm{N}, 2^{\circ} \mathrm{W}\right)$ & Coast $\left(15^{\circ} \mathrm{N}, 15^{\circ} \mathrm{W}\right)$ & Ocean $\left(15^{\circ} \mathrm{N}, 22^{\circ} \mathrm{W}\right)$ \\
\hline $\mathrm{CAPE}(\mathrm{J} / \mathrm{kg})$ & 811 & 1084 & 82 \\
$\mathrm{CIN}(\mathrm{J} / \mathrm{kg})$ & 37 & 18 & 118 \\
\hline
\end{tabular}

CAPE is the maximum energy available to ascending a parcel from its level of free convection to its equilibrium level.

$$
\mathrm{CAPE}=-\int_{\mathrm{LFC}}^{\mathrm{EL}}\left(T_{v a}-T_{v}\right) \cdot R \cdot d(\ln (P)),
$$

where LFC: is the level of free convection; EL is the equilibrium level; $R$ : is the ideal gas constant for dry air; $T_{v}$ : is the virtual temperature of the parcel; $T_{v a}$ : is the virtual temperature of environmental air; $P$ : is the pressure; $P_{s}$ : is the surface pressure.

Higher (lower) values of CAPE (CIN) indicate greater potential for severe weather. Both CAPE and CIN are among the best indexes for determining the instability of atmospheric layers.

Using daily NCEP/NCAR reanalysis data, the CAPE and the CIN were computed at three different positions of the AEW trough for each disturbance: when the AEW troughs were located over the continent, when they reach the West African coast and when they are located over the eastern North Atlantic Ocean using the information from Figure 9. Table 1 shows the values of CAPE and CIN for the AEW associated with a cyclone and for the non-developing AEW, respectively. In the case of the AEW associated with a cyclone, the CAPE values increase from the continent to the ocean (from $787 \mathrm{~J} \mathrm{~kg}^{-1}$ to $1251 \mathrm{~J} \mathrm{~kg}^{-1}$ ) while the CIN values decrease dramatically (from $74 \mathrm{~J} \mathrm{~kg}^{-1}$ to $0 \mathrm{~J} \mathrm{~kg}^{-1}$ ). Such an atmosphere is highly unstable and favorable for deep convection. In the case of the non-developing AEW, the CAPE values increase from the land to the coast, and decrease from the coast to the ocean $\left(82 \mathrm{~J} \mathrm{~kg}^{-1}\right)$, while the CIN values decrease from the land to the coast and increase from the coast to the ocean $\left(118 \mathrm{~J} \mathrm{~kg}^{-1}\right)$. This situation is less favourable for tropical cyclogenesis. However, as the CAPE and the CIN are very dependent on the choice of the ascending air parcel, it is difficult, using data at daily time scale, to discuss the important impact of sea breeze (below $900 \mathrm{hPa}$ ) and on the diurnal cycle which may affect values of these indexes in Dakar. Moreover, the calculation of CAPE and CIN with NCEP/NCAR may be also dependent on the model convective parameterization because of the fact that Africa is data sparse region (absence of many soundings).

Finally these results suggest that the propagation in an unstable environment (from the continent to the ocean) of strong low levels vortices collocated with a high humidity and an upper level support may be essential for the genesis of hurricane FRAN.

\section{Conclusions and Outlook}

Previous studies have shown that although the number of AEWs in the tropical Atlantic is fairly constant from year to year, there is a substantial variability in the fraction of AEWs that develop into tropical cyclones [19].

The objective of this work was to understand the main differences over the African continent between an AEW that developed into a cyclone and AEW that did not. We did not consider synoptic disturbances after the genesis of associated cyclones or beyond $30^{\circ} \mathrm{W}$ over the Ocean. Thus, we did not deal with the behaviour of the cyclones over the Main Development Region (MDR). The MDR is the Atlantic Ocean region that lies between $10^{\circ} \mathrm{N}$ and $20^{\circ} \mathrm{N}$ and corresponds to the main cyclogenesis area over the North Atlantic [43].

A statistical study showed that between 1989 and 2003 (a period of 15 years), 48 cyclones were born in the eastern part of the MDR. These cyclones had generally a long lifecycle. Moreover, they were all associated with AEWs which are coming from the southern track as well as from the northern track but especially from the southern track.

A composite study of the characteristics of these AEWs before their genesis days was carried out and these characteristics were compared to those of non-developing AEWs. Developing AEWs are associated with the highest PV and negative intensity of the meridional gradient of the PV over the continent and further over the North Atlantic Ocean suggesting that developing AEWs are stronger than nondeveloping AEWs. Moreover, developing AEWs are more active (greater mean relative vorticity at $850 \mathrm{hPa}$ ) over the continent and the ocean. From the point of view of the thermodynamic, highest values of potential of convection are found for developing AEWs indicating that the atmosphere is more unstable in this case. This is consistent with the existence of stronger convection and of a monsoon stronger and deeper in latitude. All these characteristics over West Africa and the North Atlantic Ocean for developing AEWs confirm the existence of a more favourable environment 
for tropical cyclogenesis. This composite study suggests that dynamic and thermodynamic conditions are both essential parameters for the development of an AEW into a cyclone.

A case study of the characteristics of an AEW associated with hurricane Fran was carried out and compared to a non-developing AEW. The rawinsonde data from Dakar station showed that the AEW associated with a cyclone is characterized by the existence of high humidity from the surface to the upper levels; while the non-developing AEW is associated with a Saharan Air Layer event which may prevent it to develop into a cyclone. The computation of CAPE and CIN confirms that the atmosphere is highly unstable in the case of the AEW associated with a cyclone; CAPE values increasing from the continent to the ocean while CIN values decreasing dramatically. From this study, it appears that the development of the AEW to Hurricane Fran is the result of the conjunction of favourable conditions: strong low-levels vortices, high humidity, an unstable environment, and an upper level support. Composite and case studies show that favourable conditions for cyclonic activity for the case of developing AEWs are present over the North Atlantic as well as over Africa, suggesting that North Atlantic cyclonic activity may be forecasted from Africa.

Research on North Atlantic TCs precursors over the African continent will be continued through modelling studies. The differences between developing AEWs and nondeveloping AEWs will be depicted by performing sensitivity studies with regional climate models. This study needs to be continued further using data with a better temporal resolution. Interactions between AEWs and active/inactive phase of the West African monsoon as well as with dry intrusions from the Saharan Air Layer and mid-latitude need to be investigated to better understand and define atmospheric characteristics over the African continent and Eastern Atlantic that are potential precursors to the development of North Atlantic TCs.

\section{Acknowledgments}

The authors are indebted to the Climate Diagnostics Center (NOAA, Boulder, CO) for providing the NCEP/ NCAR reanalysis database available at http://www.esrl.noaa .gov/psd/, to Brian Doty for the availability of GRADS software, and to the National Meteorological Office of Senegal for providing the rawinsonde data of Dakar station for the year 1996. Moctar Camara is supported by "Projet First du Ministère de la Recherche Scientifique du Sénégal" and the University of Ziguinchor, Senegal.

\section{References}

[1] W. M. Gray, "Global view of the origin of tropical disturbances and storms," Monthly Weather Review, vol. 96, pp. 669-700, 1968.

[2] W. M. Gray, "Hurricanes: their formation, structure and likely role in the tropical circulation," in Meteorology over the Tropical Oceans, D. B. Shaw, Ed., pp. 155-218, Royal Meteorological Society, Bracknall, UK, 1979.
[3] C. W. Landsea, "A climatology of intense (or major) Atlantic hurricanes," Monthly Weather Review, vol. 121, no. 6, pp. 1703-1713, 1993.

[4] T. C. Chen, S. Y. Wang, and A. J. Clark, "North Atlantic hurricanes contributed by African esterly waves north and south of the African easterly jet," Journal of Climate, vol. 21, no. 24, pp. 6767-6776, 2008.

[5] R. S. Ross and T. N. Krishnamurti, "Low-level African easterly wave activity and its relation to Atlantic tropical cyclogenesis in 2001," Monthly Weather Review, vol. 135, no. 12, pp. 39503964, 2007.

[6] G. Berry, C. Thorncroft, and T. Hewson, "African easterly waves during 2004-analysis using objective techniques," Monthly Weather Review, vol. 135, no. 4, pp. 1251-1267, 2007.

[7] M. Camara, A. Diedhiou, and A. T. Gaye, "Spatial and temporal distribution of North Atlantic cyclones," African Journal of Environmental Science and Technology, vol. 4, no. 1, pp. 477483, 2010.

[8] R. W. Burpee, "The origin and structure of easterly waves in the lower troposphere of north Africa," Journal of the Atmospheric Sciences, vol. 29, pp. 77-90, 1972.

[9] C. D. Thorncroft, N. M. J. Hall, and G. N. Kiladis, "Threedimensional structure and dynamics of African easterly waves. Part III: genesis," Journal of the Atmospheric Sciences, vol. 65, no. 11, pp. 3596-3607, 2008.

[10] I. Pytharoulis and C. Thorncroft, "The low-level structure of African easterly waves in 1995," Monthly Weather Review, vol. 127, no. 10, pp. 2266-2280, 1999.

[11] A. Diedhiou, S. Janicot, A. Viltard, P. De Felice, and H. Laurent, "Easterly wave regimes and associated convection over West Africa and tropical Atlantic: results from the NCEP/NCAR and ECMWF reanalyses," Climate Dynamics, vol. 15, no. 11, pp. 795-822, 1999.

[12] T. N. Carlson, "Some remarks on African disturbances and their progress," Monthly Weather Review, vol. 97, pp. 716-728, 1969.

[13] G. Gu, R. F. Adler, G. J. Huffman, and S. Curtis, "African easterly waves and their association with precipitation," Journal of Geophysical Research D: Atmospheres, vol. 109, no. 4, Article ID D04101, 12 pages, 2004.

[14] A. Mekonnen, C. D. Thorncroft, and A. R. Aiyyer, "Analysis of convection and its association with African easterly waves," Journal of Climate, vol. 19, no. 20, pp. 5405-5421, 2006.

[15] J. M. Futyan and A. D. Del Genio, "Deep convetive system evolution over Africa and the tropical atlantic," Journal of Climate, vol. 20, no. 20, pp. 5041-5060, 2007.

[16] C. W. Landsea, G. D. Bell, W. M. Gray, and S. B. Goldenberg, "The extremely active 1995 Atlantic hurricane season: environmental conditions and verification of seasonal forecasts," Monthly Weather Review, vol. 126, no. 5, pp. 1174-1193, 1998.

[17] S. B. Goldenberg, C. W. Landsea, A. M. Mestas-Nuñez, and W. M. Gray, "The recent increase in Atlantic hurricane activity: causes and implications," Science, vol. 293, pp. 474-479, 2001.

[18] C. Thorncroft and K. Hodges, "African easterly wave variability and its relationship to Atlantic tropical cyclone activity," Journal of Climate, vol. 14, no. 6, pp. 1166-1179, 2001.

[19] L. A. Avila and R. J. Pasch, "Atlantic tropical systems of 1991," Monthly Weather Review, vol. 120, no. 11, pp. 2688-2696, 1992.

[20] R. J. Pasch, M. B. Lawrence, L. A. Avila, J. L. Beven, J. L. Franklin, and S. R. Stewart, "Atlantic hurricane season of 2002," Monthly Weather Review, vol. 132, no. 7, pp. 1229-1289, 2004. 
[21] L. A. Avila, R. J. Pasch, and J. G. Jiing, "Atlantic tropical systems of 1996 and 1997: years of contrasts," Monthly Weather Review, vol. 128, no. 10, pp. 3695-3706, 2000.

[22] S. B. Hopsch, C. D. Thorncroft, and K. R. Tyle, "Analysis of African easterly wave structures and their role in influencing tropical cyclogenesis," Monthly Weather Review, vol. 138, no. 4, pp. 1399-1419, 2010.

[23] E. Kalnay, M. Kanamitsu, R. Kistler et al., "The NCEP/NCAR 40-year reanalysis project," Bulletin of the American Meteorological Society, vol. 77, no. 3, pp. 437-471, 1996.

[24] A. F. Krueger and A. Grueber, "The status of NOAA Ougoing longwave radiation data set," Bulletin of the American Meteorological Society, vol. 65, pp. 958-962, 1984.

[25] M. Farge, "Wavelet transforms and their applications to turbulence," Annual Review of Fluid Mechanics, vol. 24, no. 1, pp. 395-457, 1992.

[26] C. Torrence and G. P. Compo, "A Practical Guide to Wavelet Analysis," Bulletin of the American Meteorological Society, vol. 79, no. 1, pp. 61-78, 1998.

[27] C. D. Thorncroft and B. J. Hoskins, "An idealized study of African easterly waves. I: a linear view," Quarterly JournalRoyal Meteorological Society, vol. 120, no. 518, pp. 953-982, 1994.

[28] M. Dickinson and J. Molinari, "Climatology of sign reversals of the meridional potential vorticity gradient over Africa and Australia," Monthly Weather Review, vol. 128, no. 11, pp. 38903900, 2000.

[29] J. G. Charney and M. E. Stern, "On the stability of internal baroclinic jets in a rotating atmosphere," Journal of the Atmospheric Sciences, vol. 19, pp. 159-172, 1962.

[30] K.-H. Lau and N.-C. Lau, "Observed structure and propagation characteristics of tropical summertime synoptic scale disturbances," Monthly Weather Review, vol. 118, no. 9, pp. 1888-1913, 1990.

[31] D. C. Norquist, E. E. Recker, and R. J. Reed, "The energetics of African wave disturbances as observed during phase III of GATE," Monthly Weather Review, vol. 105, pp. 334-342, 1977.

[32] C. D. Thorncroft and B. J. Hoskins, "An idealized study of African easterly waves. II: a nonlinear view," Quartlery Journal_Royal Meteorological Society, vol. 120, no. 518, pp. 983-1015, 1994.

[33] J. Molinari, D. Knight, M. Dickinson, D. Vollaro, and S. Skubis, "Potential vorticity, easterly waves, and eastern Pacific tropical cyclogenesis," Monthly Weather Review, vol. 125, no. 10, pp. 2699-2708, 1997.

[34] C. D. Thorncroft and M. Blackburn, "Maintenance of the African easterly jet," Quarterly Journal of the Royal Meteorological Society, vol. 125, no. 555, pp. 763-786, 1999.

[35] W. M. Gray and C. W. Landsea, "African rainfall as a precursor of hurricane-related destruction on the US east coast," Bulletin-American Meteorological Society, vol. 73, no. 9, pp. 1352-1364, 1992.

[36] J. P. Grist, S. E. Nicholson, and A. I. Barcilon, "Easterly waves over Africa. Part II: observed and modeled contrasts between wet and dry years," Monthly Weather Review, vol. 130, no. 2, pp. 212-225, 2002.

[37] C. W. Landsea and W. M. Gray, "The strong association between Western Sahelian monsoon rainfall and intense Atlantic hurricanes," Journal of Climate, vol. 5, pp. 435-453, 1992.

[38] K. A. Emanuel, "The finite-amplitude nature of tropical cyclogenesis," Journal of the Atmospheric Sciences, vol. 46, no. 22, pp. 3431-3456, 1989.
[39] R. E. Newell and J. W. Kidson, "African mean wind changes between Sahelian wet and dry periods," Journal of Climatology, vol. 4, no. 1, pp. 27-33, 1984.

[40] J. M. Prospero and T. N. Carlson, "Radon-222 in the North Atlantic trade winds: its relationship to dust transport from Africa," Science, vol. 167, no. 3920, pp. 974-977, 1970.

[41] J. J. Walsh and K. A. Steidinger, "Saharan dust and Florida red tides: the cyanophyte connection," Journal of Geophysical Research C: Oceans, vol. 106, no. 6, pp. 11597-11612, 2001.

[42] J. P. Dunion and C. S. Marron, "A reexamination of the Jordan mean tropical sounding based on awareness of the Saharan air layer: results from 2002," Journal of Climate, vol. 21, no. 20, pp. 5242-5253, 2008.

[43] S. B. Goldenberg and L. J. Shapiro, "Physical mechanisms for the association of El Niño and west African rainfall with Atlantic major hurricane activity," Journal of Climate, vol. 9, no. 6, pp. 1169-1187, 1996. 

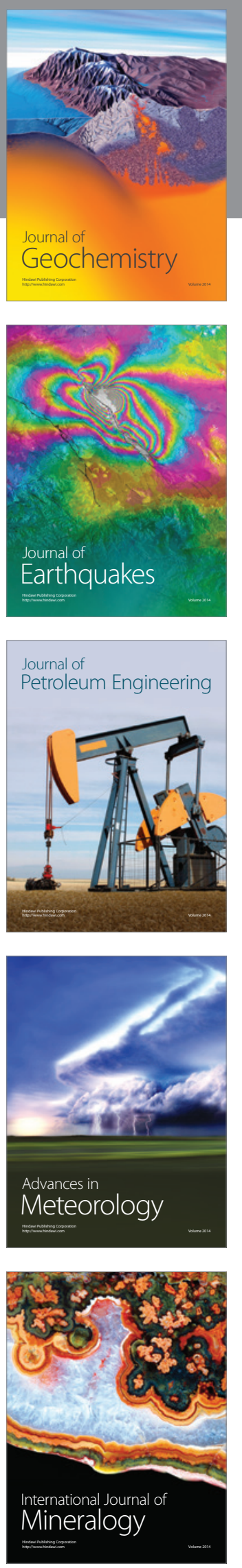
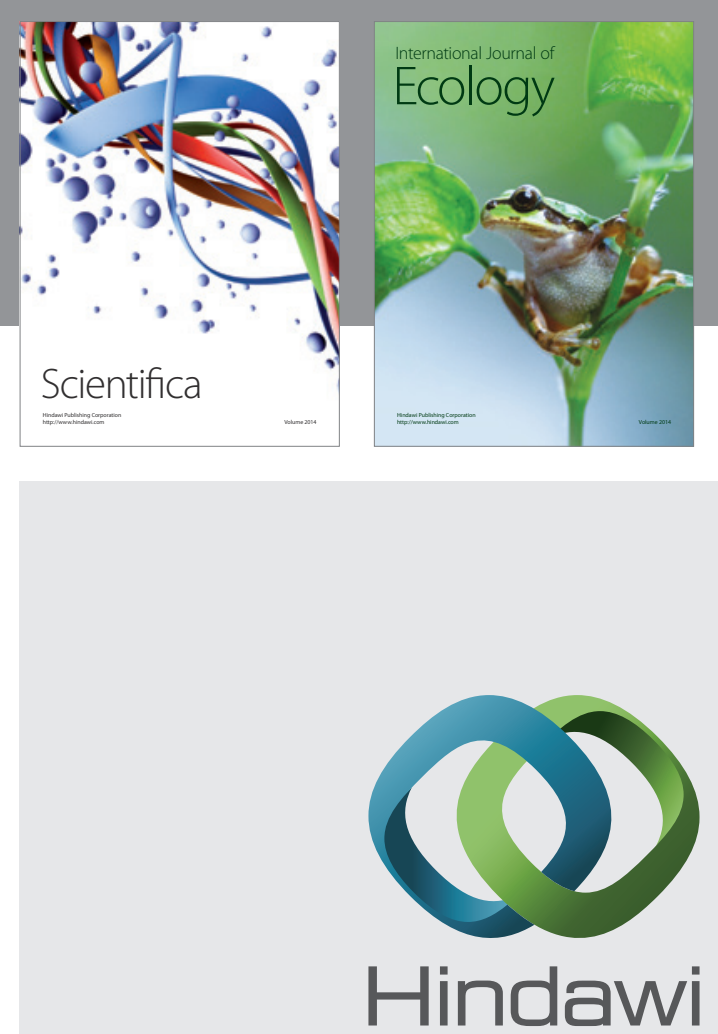

Submit your manuscripts at http://www.hindawi.com
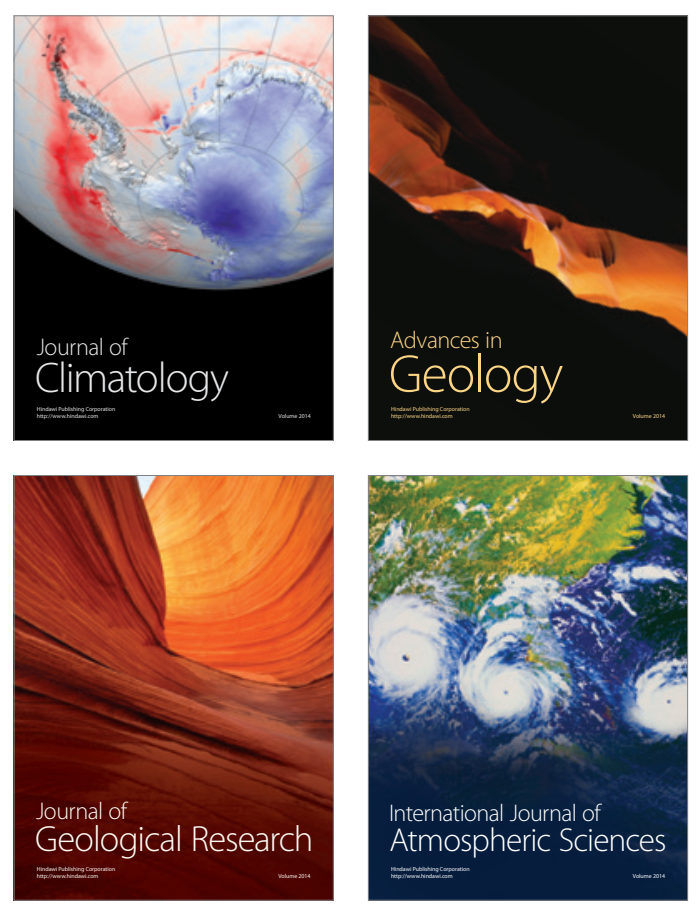
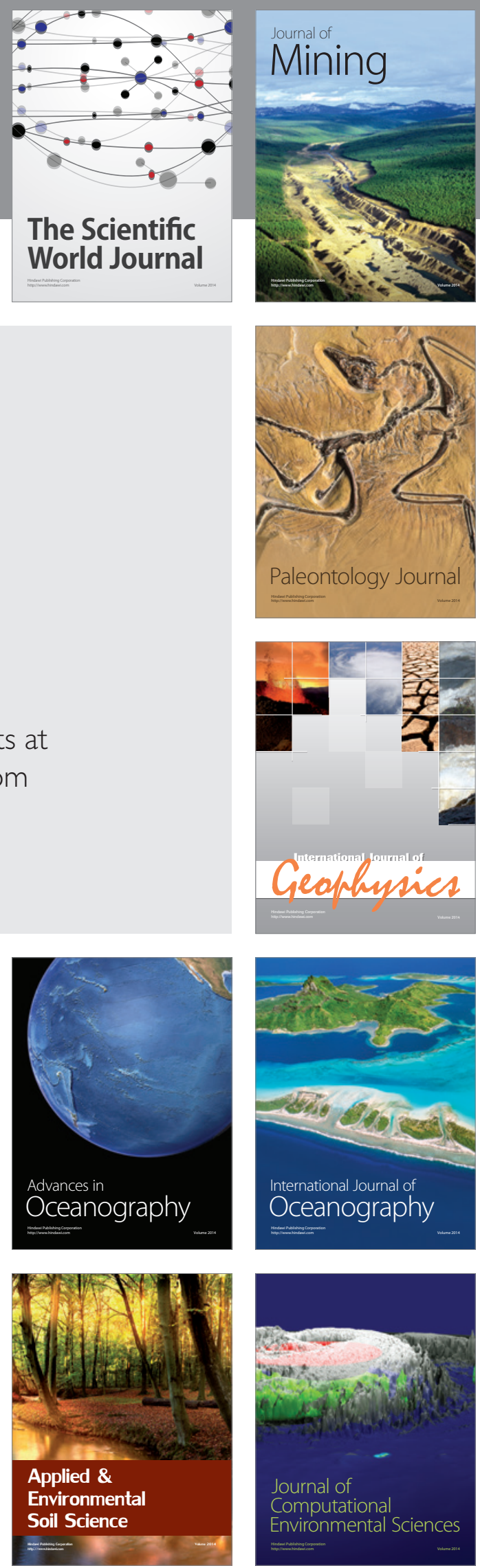